\title{
The utility of high-resolution intraoperative MRI in endoscopic transsphenoidal surgery for pituitary macroadenomas: early experience in the Advanced Multimodality Image Guided Operating suite
}

\author{
Hasan A. Zaidi, MD, ${ }^{1}$ Kenneth De Los Reyes, MD, ${ }^{1}$ Garni Barkhoudarian, MD, ${ }^{1}$ \\ Zachary N. Litvack, MD, MCR, ${ }^{1}$ Wenya Linda Bi, MD, PhD, ${ }^{1}$ Jordina Rincon-Torroella, ${ }^{1}$ \\ Srinivasan Mukundan Jr., PhD, MD, ${ }^{2}$ Ian F. Dunn, MD, ${ }^{1}$ and Edward R. Laws Jr., MD' ${ }^{1}$ \\ Departments of ${ }^{1}$ Neurosurgery and ${ }^{2}$ Radiology, Brigham and Women's Hospital, Harvard Medical School, Boston, \\ Massachusetts
}

\begin{abstract}
OBJECTIVE Endoscopic skull base surgery has become increasingly popular among the skull base surgery community, with improved illumination and angled visualization potentially improving tumor resection rates. Intraoperative MRI (iMRI) is used to detect residual disease during the course of the resection. This study is an investigation of the utility of 3-T iMRI in combination with transnasal endoscopy with regard to gross-total resection (GTR) of pituitary macroadenomas.

METHODS The authors retrospectively reviewed all endoscopic transsphenoidal operations performed in the Advanced Multimodality Image Guided Operating (AMIGO) suite from November 2011 to December 2014. Inclusion criteria were patients harboring presumed pituitary macroadenomas with optic nerve or chiasmal compression and visual loss, operated on by a single surgeon.
\end{abstract}

RESULTS Of the 27 patients who underwent transsphenoidal resection in the AMIGO suite, 20 patients met the inclusion criteria. The endoscope alone, without the use of iMRI, would have correctly predicted extent of resection in 13 $(65 \%)$ of 20 cases. Gross-total resection was achieved in 12 patients (60\%) prior to MRI. Intraoperative MRI helped convert 1 STR and 4 NTRs to GTRs, increasing the number of GTRs from $12(60 \%)$ to $16(80 \%)$.

CONCLUSIONS Despite advances in visualization provided by the endoscope, the incidence of residual disease can potentially place the patient at risk for additional surgery. The authors found that iMRI can be useful in detecting unexpected residual tumor. The cost-effectiveness of this tool is yet to be determined.

http://thejns.org/doi/abs/10.3171/2016.1.FOCUS15515

KEY WORDS intraoperative MRI; endoscope; pituitary adenomas; resection; AMIGO

A DVANCES in pituitary surgery have paralleled technological innovations of the last century. From its original description by Schloffer to Hardy's introduction of the operating microscope and fluoroscopy, and more recently Jho and Carrau's endoscopic technique, several groups have demonstrated a stepwise improvement in safety and efficacy in the resection of parasellar lesions. ${ }^{8,12}$ Each technical and technological innovation has served the purpose of achieving safe and effective maximal tumor resection while preserving normal pituitary gland and optic nerve function. The goals of resection of pituitary macroadenomas have always been to maximize tumor re- section, increase the chance of endocrine remission, and lower the risk of tumor recurrence. ${ }^{11,14,17,18,24,28}$

The concept of providing the surgeon with immediate MRI assessment of residual disease during the resection of pituitary tumors by means of a scanner in the surgical suite was first realized in Boston at the Brigham and Women's Hospital in 1994. ${ }^{22}$ There has been considerable literature in support of intraoperative MRI (iMRI) for achieving greater extent of resection for a variety of intracranial tumors. With regard to microscopic transsphenoidal surgery, several groups have demonstrated efficacy in resecting residual tumor in the parasellar gutters, tumor 
tissue that would have otherwise been left behind with a traditional microscopic view. ${ }^{3,27,29}$ In the last decade, many skull base surgery centers have transitioned from a fully microscopic visualization modality to a fully endoscopically driven approach. The endoscope affords greater illumination, and angled endoscopes allow for visualization around corners for resection of residual disease. Little is known regarding the utility of iMRI in the modern endoscopic era. ${ }^{26,28}$ Some suggest that because of the greater visualization provided by the endoscope versus the microscope, iMRI may be not be essential.

In light of these criticisms, we set out to investigate the utility of 3-T iMRI in combination with transnasal endoscopy with regard to gross-total resection (GTR) of pituitary macroadenomas. The Advanced Multimodality Image Guided Operating (AMIGO) suite at the Brigham and Women's Hospital harnesses the power of high-field 3-T iMRI and integrated neuronavigation. We reviewed the experience with our initial 20 cases of pituitary macroadenomas operated upon by means of an endoscopic transsphenoidal approach in the AMIGO suite.

\section{Methods}

\section{Inclusion and Exclusion Criteria}

We retrospectively reviewed all 27 endoscopic transsphenoidal operations performed in the AMIGO suite from November 2011 to December 2014. Inclusion criteria for this study were patients harboring presumed pituitary macroadenomas with optic nerve or chiasmal compression and visual loss, surgically resected by one of two experienced transsphenoidal surgeons (E.R.L. or I.D.). All tumors had suprasellar extension. Exclusion criteria were pituitary microadenomas ( $<10 \mathrm{~mm}$ diameter), patient age $<18$ years or $>80$ years, and pregnancy. Our surgical selection criteria for treating patients in the AMIGO suite are lesions with extensive suprasellar extension, parasellar extension, encasement of anterior circulation vasculature, or visual compromise with giant lesions. We recorded the demographic, clinical, and endocrine history and imaging findings as well as intraoperative observations. The study was approved by the Brigham and Women's Hospital, Harvard Medical School institutional review board.

\section{Surgical and Imaging Techniques}

All patients were operated upon using a standard institutional protocol for transsphenoidal surgery. The preoperative MRI technique includes whole-brain diffusion-weighted, axial FLAIR, axial T2-weighted, and postcontrast 3D FSGR (fat spoiled gradient echo) T1-weighted sequences. Dedicated sellar imaging includes pre- and post-contrast sagittal T1-weighted images ( $3 \mathrm{~mm}$ slice thickness), preand post-contrast coronal T1-weighted images, and sagittal 3D FIESTA (fast imaging employing steady-state acquisition) sequences with coronal reformatting. We include the 3D FSGR for purposes of neuronavigation with the BrainLab system. The 3D FIESTA allows for high-resolution multiplanar reformatting and is used for MRI cisternography. All patients were evaluated in a multidisciplinary pituitary/neuroendocrine center, where their neurological and biochemical endocrine status was assessed.
While the patient is in the preoperative holding area (before entering the AMIGO suite), the surgical team and MRI technologists perform a careful review using an extensive checklist to ensure that only MRI-compatible equipment is in place and that the patient has no metal implants and is free of any other metal objects. The patient is orally intubated and intravenous lines are placed. The patient's head is placed in an MRI-compatible Mayfield head holder (Medtronic) and then positioned with lateral rotation to the right shoulder and coronal translation toward the left shoulder, and with the head in mild flexion so that the bridge of the nose is parallel to the floor. Neuronavigation is then registered and accuracy is confirmed. A 2D high-definition rigid endoscope (Karl Storz) or a 3D standard-definition endoscope (Visionsense) is used for visualization. After standard endonasal exposure of the sella, including a posterior septectomy and removal of the rostral sphenoid sinus, a micro-Doppler probe is used to confirm the location of the cavernous carotid arteries. A careful incision is made into the dura, and dural leaves are reflected or excised. The adenoma is identified and removed in standard fashion, using forceps, suction, and a variety of ring curettes, until all visualized tumor is removed and the diaphragma sellae has descended. A $30^{\circ}$ or $45^{\circ}$ endoscope is then used to assess for and resect residual tumor. The defect is filled with Gelfoam temporarily during the intraoperative imaging to minimize signal loss on the MRI due to magnetic susceptibility artifact from free air. It is imperative that the surgical cavity be as free from blood products as possible, as we have found that their presence frequently results in misinterpretation of the iMRI. This can often be difficult to achieve, and for this reason, we spend a tremendous amount of time achieving hemostasis prior to initiating intraoperative image acquisition.

The patient is then undraped, keeping all the instruments and trays sterile. The back table is safely moved far out of reach of the MRI magnetic field. The table is rotated to allow for the iMRI unit (3T Siemens Verio, IMRIS modified) to slide into the room for imaging acquisition. This occurs while the patient's head remains in the Mayfield head clamp and the patient is kept sedated with general endotracheal anesthetic agents. The iMRI gantry is in an adjacent room on a track embedded in the floor. The gate separating the gantry and the operating room is opened, the MRI gantry is slid into the operating room, and the iMRI is acquired in the surgical area (Fig. 1). There was some variability with regard to sequences that were performed. Overall, the MRI sequences performed included coronal and sagittal images (3 $\mathrm{mm}$ slice thickness) obtained before and both 5 and 10 minutes after injection of a gadolinium contrast agent (Magnevist, $0.1 \mathrm{mmol} / \mathrm{kg}$ ). Early in our experience, we used dynamic imaging that provided little help in differentiating tumor. Later on in our experience, axial T2-weighted and diffusion-weighted sequences were used to better assess blood products. A neuroradiologist is present during the sequence acquisition and immediately interprets the images independently. When there is concern for residual tumor, the surgeon is alerted and the area in question is thoroughly explored both with imaging and surgically.

Systematic re-exploration is performed in all cases; any 

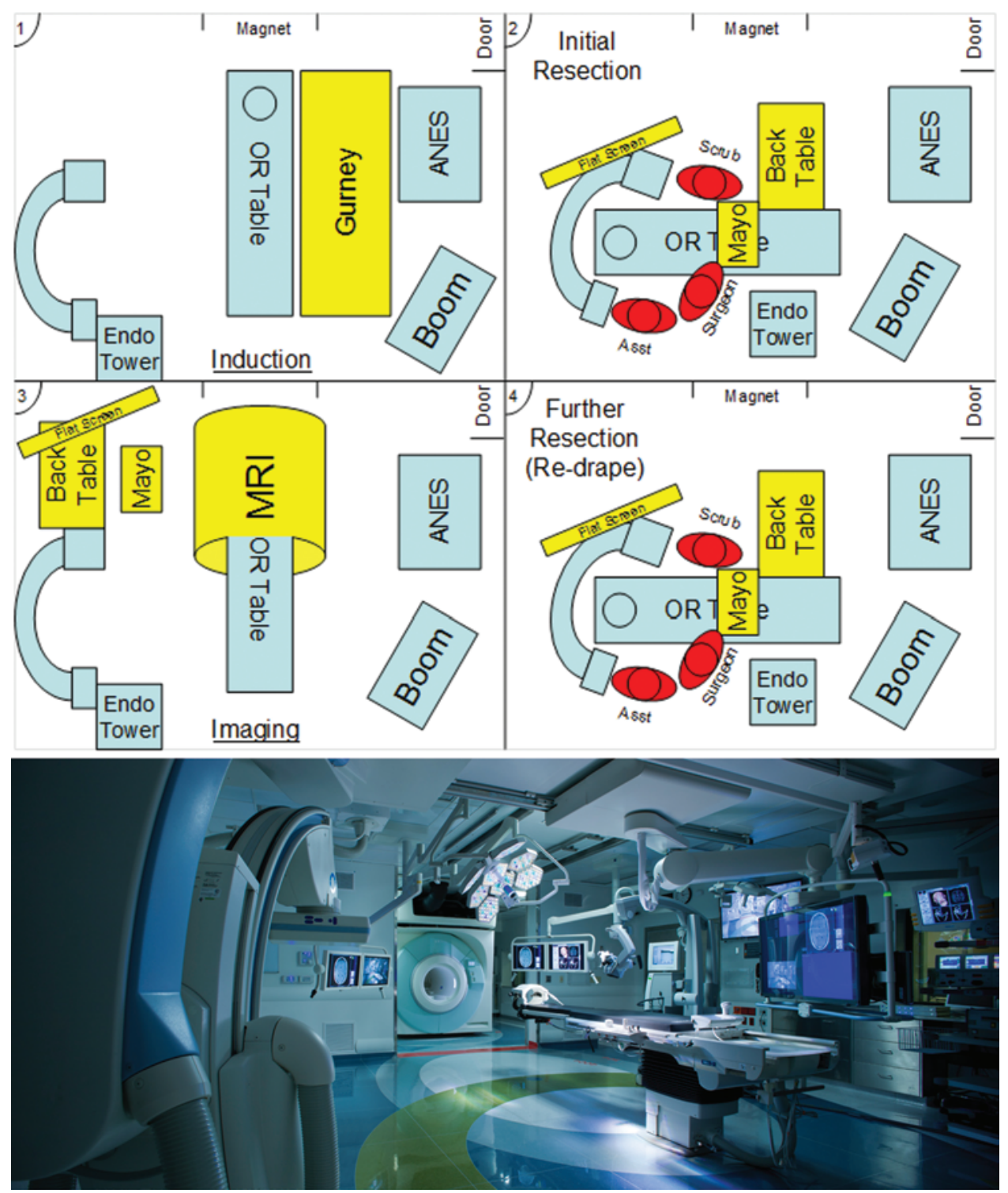

FIG. 1. Upper: Illustrative diagram demonstrating the setup of the operating room in the AMIGO suite from induction (panel 1), initial resection (panel 2), intraoperative MR image (panel 3), and systematic reexploration (panel 4). Lower: Photograph of the AMIGO suite, with the gate separating the surgical area and the MRI gantry open. Patients remain stationary while the MRI scanner is rolled into the room via tracks built into the floor. ANES = anesthesiology; Asst = assistant; Endo = endoscopy; Mayo = Mayo table; OR = operating room.

area of concern is re-assessed, and if a specimen is obtained it is sent separately for pathological evaluation. We follow a systematic method in re-exploring the surgical cavity for residual disease. Paterno et al. noted that among a series of 72 patients undergoing pituitary surgery with iMRI residual disease was often found anteriorly, laterally, posteriorly, and in the suprasellar space under descending folds of the diaphragm. ${ }^{21}$ For these reasons, we first place a $0^{\circ}$ endoscope in the surgical cavity to inspect areas that are suspicious for residual disease based on the iMRI scan. If no residual disease is found, angled $30^{\circ}$ and $45^{\circ}$ endoscopes are then inserted to visualize around corners, particularly in the anterior and lateral cavities ${ }^{21}$ to confirm to investigate further. If necessary, intraoperatively acquired MRI sequences can be used in a navigation system to improve the chance of successful identification and removal of residual disease. An additional iMRI scan is performed to demonstrate adequate optic apparatus decompression when needed. The surgical field is inspected for CSF leaks with Valsalva maneuvers. All suspected CSF leaks are repaired with abdominal fat. The abdominal fat is treated with chloramphenicol, wisps of cotton fibers, and Avitene microfibrillar collagen. The treated fat grafts are inserted into the sellar defect. A MedPor (Stryker) polyethylene plate is fashioned as a solid buttress to reconstruct the sellar floor and fixed epidurally. Pledgets of Gelfoam are placed over the plate. The middle turbinates are medialized, the nose is set in the midline, and 
the posterior pharynx is suctioned prior to terminating the surgical procedure.

\section{Results}

A total of 27 patients underwent transsphenoidal surgery for pituitary tumors in the AMIGO suite, and 20 of these patients ( 9 men, 11 women) met our inclusion/exclusion criteria. The mean age of the included patients was 51.6 years (range $34-72$ years). All patients presented with visual changes as one of their primary symptoms. Eleven patients $(55.0 \%)$ had headaches. Four $(20 \%)$ presented with acromegaly. Two (10\%) had preoperative hypopituitarism: the patient in Case 6 had low testosterone and adrenal insufficiency, and the patient in Case 7 had primary hypogonadism, hypothyroidism and adrenal insufficiency. The patient in Case 11 presented with acromegaly and concomitant facial numbness due to extensive bilateral cavernous sinus invasion. The patient in Case 10 presented with MRI evidence of recurrence of a null cell adenoma. The mean maximum dimension of the tumors was $2.8 \mathrm{~cm}$ (range 1.4-4.5 cm). All tumors extended into the suprasellar space and were causing optic nerve and/or chiasm compression, with 5 (25\%) demonstrating at least a Knosp Grade 3 degree of cavernous sinus invasion (Table 1).

\section{Intraoperative Imaging}

The average iMRI acquisition time was 21.5 minutes (range 8-47 minutes). Preoperative and postoperative coronal and sagittal T1-weighted MR images were obtained in all cases. Early in our experience, dynamic imaging was performed without much utility. Diffusion-weighted and T2-weighted axial images were obtained routinely in the latter half of our series to aid in differentiating residual tumor and blood.

The iMRI interpretations agreed with the intraoperative findings in 17 (85\%) of 20 cases. In 10 of these cases, the iMRI interpretation reported expected findings; in 4 of these 10 cases, there was no observable residual tumor and in 2 (Cases 4 and 5) residual tumor was anticipated. The patient in Case 4 had a planned subtotal resection (STR) of a growth hormone $(\mathrm{GH})$-secreting tumor encasing the bilateral anterior cerebral arteries. The patient in Case 5 had residual tumor along the medial cavernous carotid artery, which was left after significant venous bleeding was encountered.

\section{Unexpected Residual Tumor Detected on iMRI}

Intraoperative MRI revealed unexpected residual tumor in $6(30 \%)$ of the 20 cases (Cases 1, 7, 10, 11, 12, and 15). The residual tumor fragments were safely removed and confirmed to be adenoma tissue on histopathological examination. The patient in Case 1 was a young man with acromegaly who had residual tumor along the right sellar floor adjacent to the medial cavernous sinus. The patient in Case 7 was a 68-year-old woman with a large nonfunctioning macroadenoma whose tumor appeared completely resected with the expected symmetric diaphragma prolapse; iMRI, however, revealed that a large suprasellar portion of the tumor remained (Figs. 2 and 3).

TABLE 1. Demographic, clinical, and imaging characteristics

\begin{tabular}{|c|c|c|c|c|c|c|c|c|c|}
\hline $\begin{array}{l}\text { Case } \\
\text { No. }\end{array}$ & $\begin{array}{l}\text { Age } \\
\text { (yrs) }\end{array}$ & Sex & Diagnosis & Recurrence & Symptoms & $\begin{array}{c}\text { Max } \\
\operatorname{Diam}(\mathrm{cm})\end{array}$ & $\begin{array}{c}\text { Tumor } \\
\text { Vol }\left(\mathrm{cm}^{3}\right)\end{array}$ & $\begin{array}{l}\text { Suprasellar } \\
\text { Extension }\end{array}$ & $\begin{array}{l}\text { Knosp } \\
\text { Grade }\end{array}$ \\
\hline 1 & 38 & M & $\mathrm{GH}$ & No & HA, acromegaly, vision loss & 2.7 & 8.3 & Yes & 0 \\
\hline 2 & 58 & M & Null cell & No & Vision loss & 4.5 & 24.9 & Yes & 2 \\
\hline 3 & 62 & $\mathrm{~F}$ & Silent GH & No & Vision loss, $\mathrm{HA}$ & 2 & 1.7 & Yes & 0 \\
\hline 4 & 41 & $\mathrm{~F}$ & $\mathrm{GH}$ & No & Acromegaly, vision loss & 3.9 & 15.8 & Yes & 3 \\
\hline 5 & 64 & M & Null cell & No & Vision loss, HA & 3.2 & 9.2 & Yes & 3 \\
\hline 6 & 19 & $\mathrm{M}$ & $\mathrm{GH}$ & No & Vision loss, HA, hypopituitarism, acromegaly & 3.4 & 8.1 & Yes & 0 \\
\hline 7 & 68 & $\mathrm{~F}$ & Null cell & No & Vision loss, hypopituitarism & 3.8 & 14.0 & Yes & 0 \\
\hline 8 & 68 & $\mathrm{~F}$ & Null cell & No & Vision loss & 2.7 & 4.3 & Yes & 2 \\
\hline 9 & 55 & $\mathrm{~F}$ & Null cell & No & Vision loss & 4.1 & 17.1 & Yes & 4 \\
\hline 10 & 51 & $\mathrm{~F}$ & Null cell & Yes & Vision loss, $\mathrm{HA}$ & 2.8 & 5.7 & Yes & 4 \\
\hline 11 & 72 & $\mathrm{~F}$ & GH PRL & No & Vision loss, $\mathrm{HA}$, acromegaly, facial numbness & 4.2 & 39.2 & Yes & 4 \\
\hline 12 & 34 & $\mathrm{~F}$ & Null cell & No & Amenorrhea, vision loss & 2.32 & 4.0 & Yes & 0 \\
\hline 13 & 64 & M & Null cell & No & Vision loss & 1.4 & 1.6 & Yes & 0 \\
\hline 14 & 52 & $\mathrm{~F}$ & Null cell & No & HA, vision loss & 1.9 & 6.1 & Yes & 0 \\
\hline 15 & 56 & M & FSH/LH NFA & No & HA, vision loss & 2.4 & 6.4 & Yes & 0 \\
\hline 16 & 50 & M & LH NFA & Yes & Vision loss & 3.2 & 25.0 & Yes & 2 \\
\hline 17 & 47 & M & Null cell & No & Vision loss, HA & 2.3 & 11.1 & Yes & 1 \\
\hline 18 & 38 & $\mathrm{~F}$ & Silent ACTH & No & HA, vision loss & 1.5 & 2.5 & Yes & 0 \\
\hline 19 & 57 & M & FSH NFA & Yes & HA, vision loss & 1.8 & 4.9 & Yes & 0 \\
\hline 20 & 38 & $F$ & Null cell & No & Vision loss & 1.9 & 4.0 & Yes & 1 \\
\hline
\end{tabular}

ACTH = adrenocorticotropic hormone; $\mathrm{CS}=$ cavernous sinus; diam = diameter; $\mathrm{FSH}=$ follicle-stimulating hormone; $\mathrm{GH}=$ growth hormone; $\mathrm{HA}=$ headache; $\mathrm{LH}=$ luteinizing hormone; PRL = prolactin; NFA = nonfunctioning adenoma. 

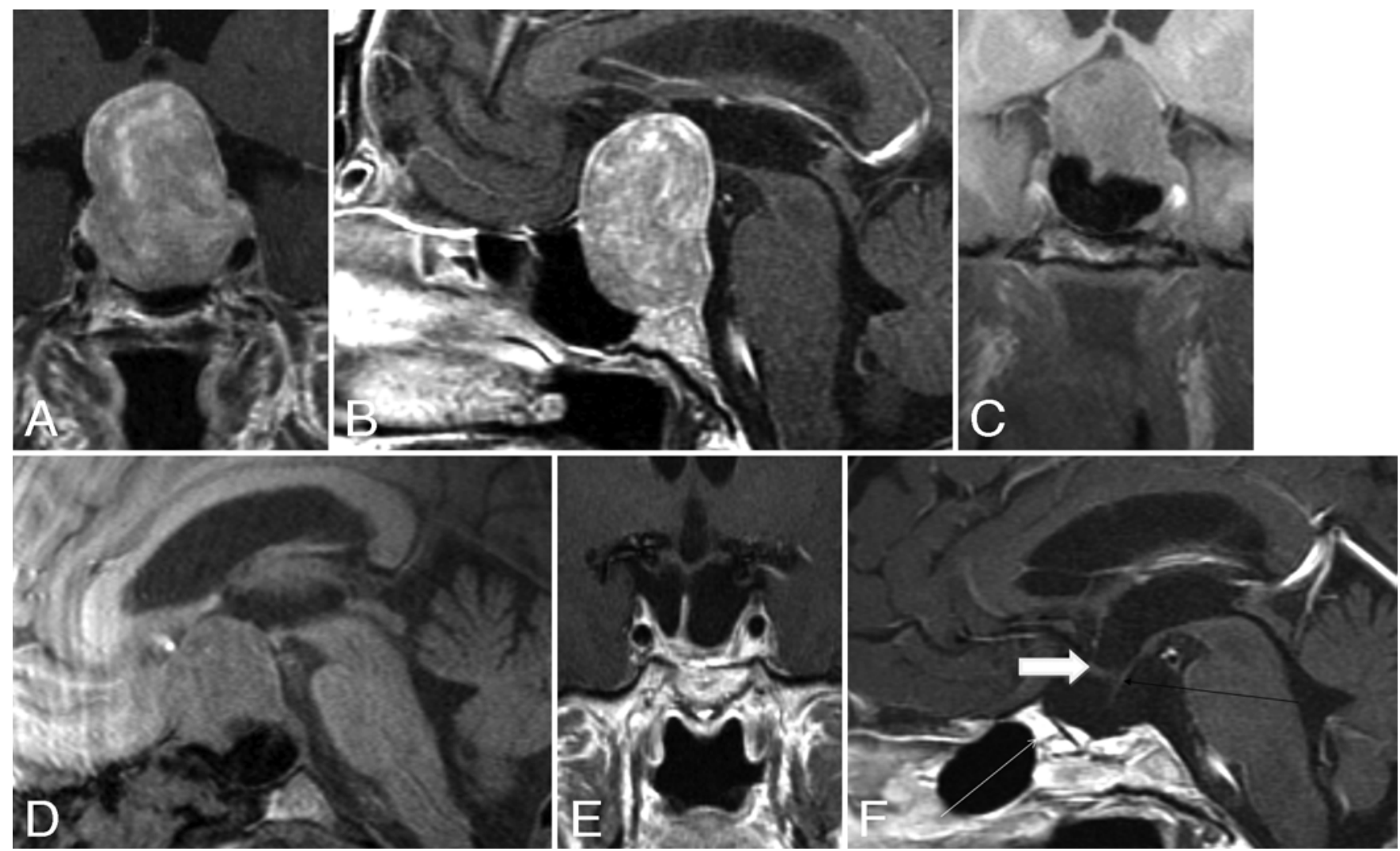

FIG. 2. Case 7. An illustrative case of unexpected residual tumor eligible for further resection, found on iMRI and not on endoscopy. A and B: Preoperative coronal (A) and sagittal (B) post-contrast T1-weighted MR images demonstrating a sellar-suprasellar macroadenoma. C and D: Coronal (C) and sagittal (D) intraoperative T1-weighted MR images obtained after initial resection and without administration of a contrast agent. Note the massive suprasellar residual (white arrow). E and F: Coronal (E) and sagittal (F) T1-weighted MR images obtained without administration of a contrast agent after re-exploration and removal of the targeted residual tumor demonstrating decompression of the optic chiasm (white thick arrow), visible infundibular stalk (black thin arrow), as well as hyperintense fat in the sella (white thin arrow).
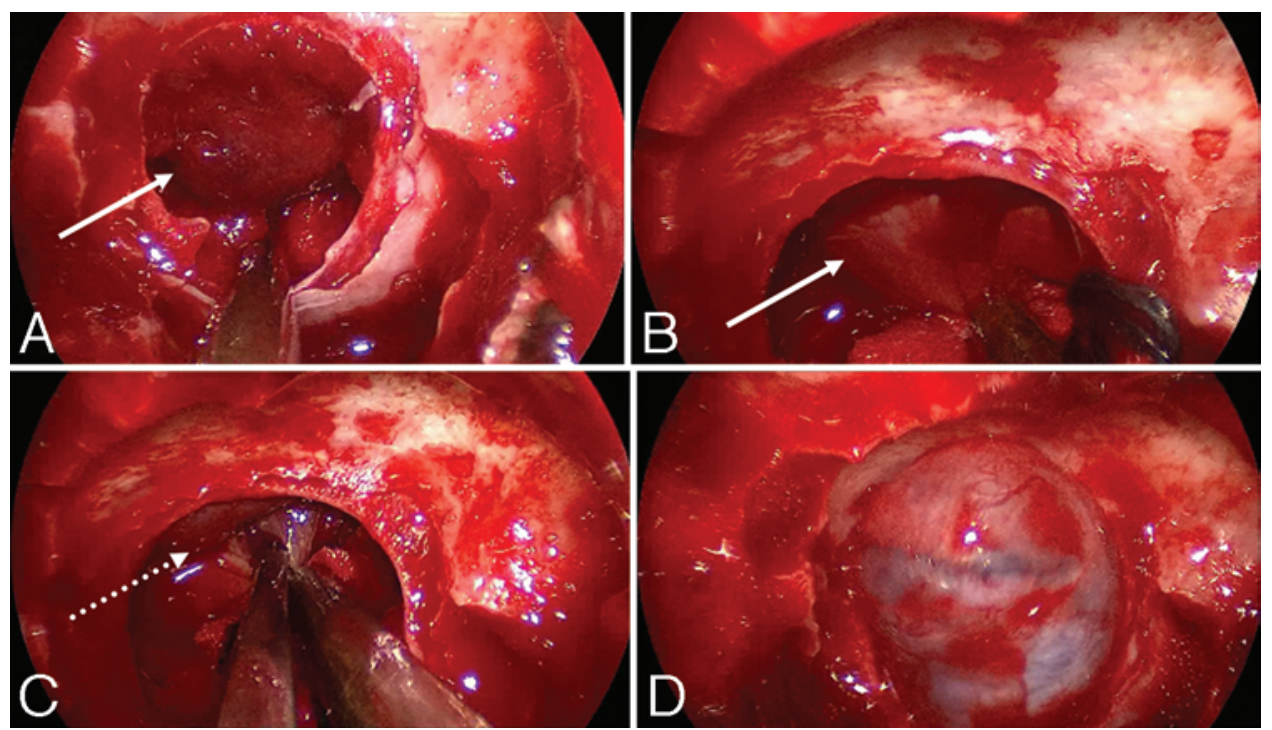

FIG. 3. Case 7. Intraoperative photographs. The white arrow in A and B points to the presumed diaphragma sellae prolapse followed by sequential dissection of this membrane away from the true diaphragma sellae in $\mathbf{C}$. The dotted arrow shows the plane between the presumed and actual diaphragma sellae. The full true diaphragma sellae prolapse in the sellar floor is demonstrated well in $\mathbf{D}$. 

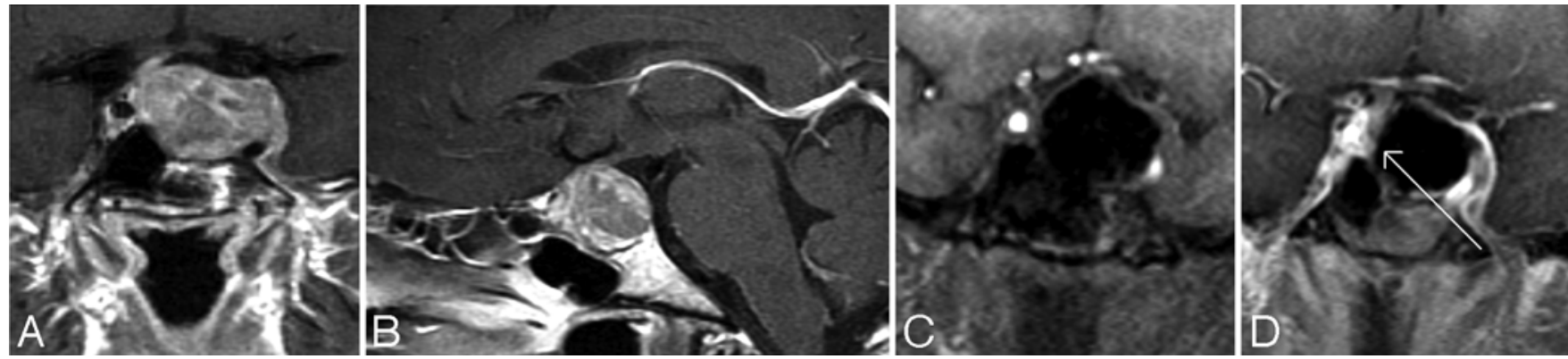

FIG. 4. Case 10. This patient presented with a recurrent nonfunctioning adenoma and visual loss. A and B: Preoperative coronal (A) and sagittal (B) Gd-enhanced T1-weighted MR images demonstrating the recurrent macroadenoma. $\mathbf{C}$ and D: Intraoperative coronal T1-weighted MR images obtained before (C) and after (D) gadolinium administration, highlighting the small accessible nodule along the right medial cavernous sinus wall (arrow) that was subsequently removed and proven to be adenoma on histopathological examination.

The patients in Cases 10, 12, and 15 had small residual nonfunctioning tumors along the cavernous carotid artery (Knosp Grade 4) (Fig. 4), a thinned-out diaphragma sella and compressed pituitary gland (Fig. 5), and an anterior fold of diaphragma sella, respectively (Fig. 6). The patient in Case 11 was a 72-year-old woman harboring a GH-secreting macroadenoma with complete bilateral cavernous carotid artery encasement (Knosp Grade 4); the goal of surgery was optic nerve decompression and STR to help the efficacy of planned postoperative medical therapy.
Intraoperative MRI demonstrated expected bilateral cavernous sinus residual tumor, but also persistent right optic nerve and chiasmal compression due to a small nodule not readily appreciated on first inspection, especially in a bloody operative field (Fig. 7; Table 2).

The endoscope alone, without the use of iMRI, would have correctly predicted $13(65.0 \%)$ of 20 cases (Table 2 ); these include 1 gross-total resection and 2 near-total resections (NTRs) or subtotal resections (STRs). Grosstotal resection was achieved in 12 patients $(60 \%)$ prior to
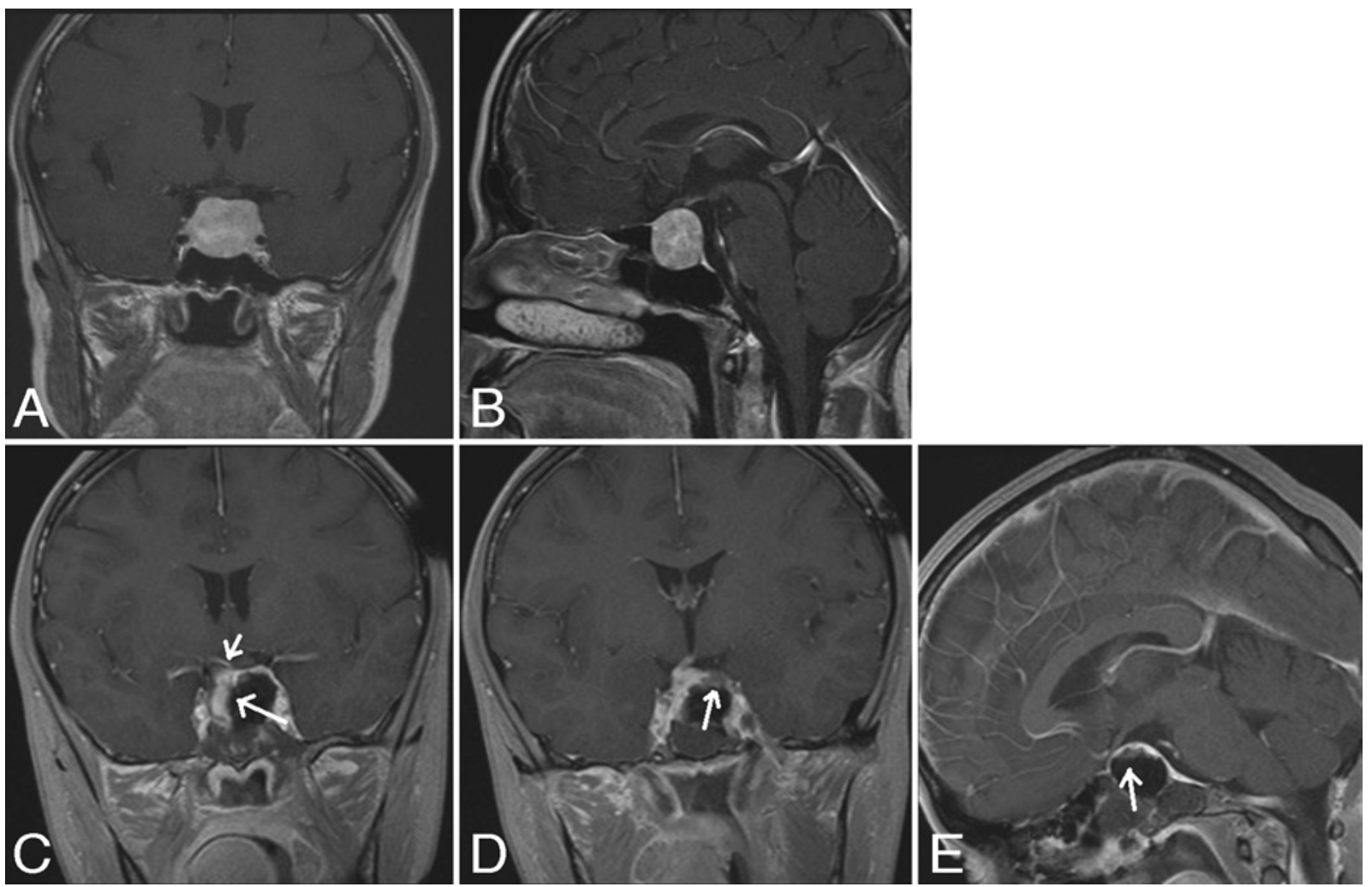

FIG. 5. Case 12. This patient presented with visual loss and was found to have a nonfunctioning adenoma. A and B: Preoperative Gd-enhanced T1-weighted MR images demonstrating the tumor. C-E: Intraoperative Gd-enhanced T1-weighted MR images highlighting a hypointense nodule (white arrow) in a fold of normal gland and diaphragma sella. The nodule was removed and proven to be adenoma on histopathological examination. 
MRI. iMRI helped convert 1 STR ( $\geq 50 \%$ resection) and 4 NTRs ( $\geq 95 \%$ resection) to GTRs, increasing the number of GTRs from $12(60 \%)$ to $16(80 \%)$.

Three iMRI reports were equivocal and provided incorrect impressions of the operative field, over-reporting "likely residual tumor," which histopathological examination showed to be blood clots in all 3 cases.

\section{Outcomes}

There were no intraoperative or immediate postoperative complications. Eight patients $(40 \%)$ had an intraoperative CSF leak treated with abdominal fat grafts; no patient had a postoperative CSF leak. One patient developed delayed sinusitis, which was treated with intravenous antibiotics.

In 16 cases $(80 \%)$, histopathological evaluation demonstrated nonfunctioning adenomas (11 null cell, 1 silent GH-secreting, 3 silent FSH/LH, and 1 silent adrenocorticotropic hormone [ACTH]-staining). Three had GH-secreting adenomas with acromegaly, and one had a GH and prolactin-secreting adenoma with acromegaly.

The mean duration of follow-up was 4.3 months (range 1.5-12 months). All patients had improvement of their headaches and visual deficits. The patient in Case 6 developed secondary hypothyroidism. The patient in Case 9 was being treated with cortisol replacement therapy because of evidence of new-onset postoperative hypoadrenalism. Two patients with acromegaly (Cases 1 and 6) were in biochemical remission at last follow-up (1 year after surgery), with IGF-1 levels and the results of oral glucose tolerance testing being within the normal range in both cases. The patients in Cases 4 and 11 (who both underwent STR) are currently being treated with sandostatin therapy, and their IGF-1 levels have improved but are not yet within the normal range (Table 3 ).

\section{Discussion}

Goals paramount to successful transsphenoidal surgery are to maximize tumor resection and achieve decompression of critical parasellar neurovascular structures while preserving normal pituitary function. Although GTR is not always possible, a variety of surgical tools have been introduced in transsphenoidal surgery in the last 2 decades in order to incrementally improve the degree of tumor resection. 1,4,17,18,24 The endoscope has become widely adopted in academic skull base centers to provide greater illumination of endonasal skull base structures and angled viewing, both of which are often suboptimal with a traditional microscopic view. Although most surgeons would agree that a better view should increase the potential for GTR and therefore improve clinical outcomes, this is speculative and has not been proven. Meta-analyses comparing endoscopic and microscopic pituitary surgery have been inconclusive; several studies report improved short-term endocrine remission and fewer complications (except for CSF leaks), particularly for patients with functioning adenomas. ${ }^{9,30}$ Rotenberg et al. demonstrated that endoscopic surgery afforded fewer complications, shorter hospital stays and greater patient comfort. ${ }^{25}$ There is a consistent lack of evidence, however, that endoscopic surgery leads

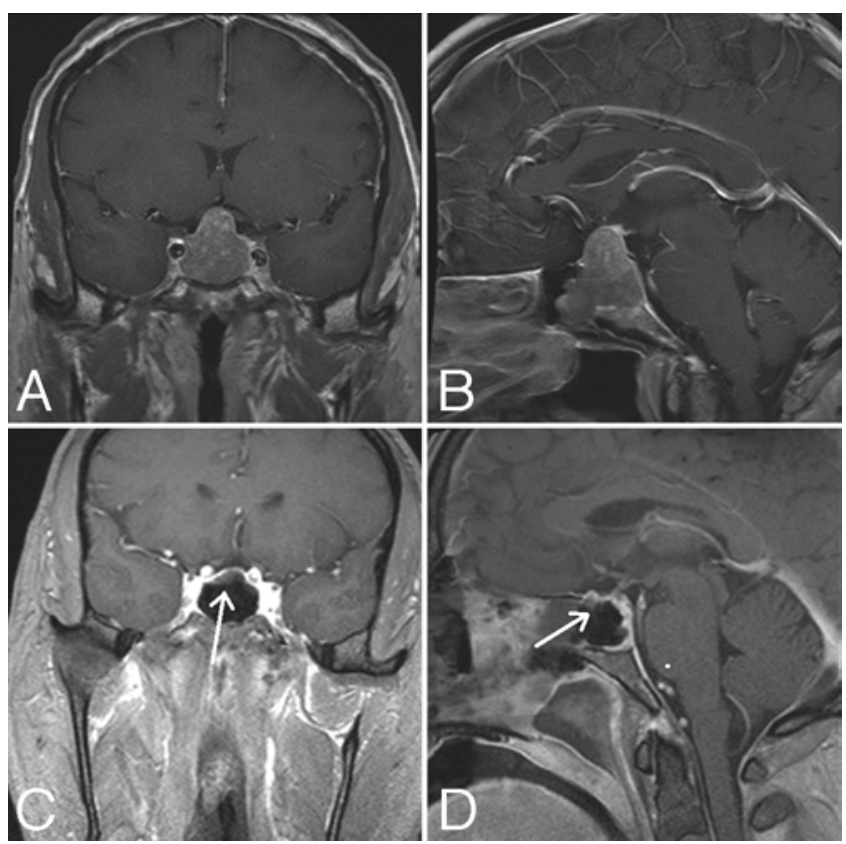

FIG. 6. Case 15. This patient presented with headaches and visual loss. A and B: Preoperative coronal (A) and sagittal (B) T1-weighted MR images demonstrating a macroadenoma. $\mathbf{C}$ and $\mathbf{D}$ : Intraoperative coronal (C) and sagittal (D) Gd-enhanced T1-weighted MR images highlighting the hypointense nodule (arrows) along an anterior fold of diaphragma sellae/pseudocapsule that was later removed and proven to be adenoma on histopathological examination.

to higher rates of GTR. In this context, intraoperative MRI may play a useful role in further improving rates of tumor resection despite the use of intrasellar endoscopy.

MRI has become the gold standard for diagnosing and characterizing sellar pathology by offering detailed soft tissue differentiation and multiplanar reconstruction. $\mathrm{Bu}-$ chfelder and Schlaffer reviewed the use of iMRI-utilizing low-field and high field magnets $(0.15-3 \mathrm{~T})$-for pituitary surgery in the last decade. ${ }^{6}$ Low-field iMRI led to further tumor resection in all series, $18 \%-65 \%$, increasing the rates of GTR. ${ }^{6}$ Despite the ability to detect accurate optic apparatus decompression (which correlates well with visual outcome improvement), ${ }^{4,15}$ both Gerlach et al. and Bellut et al. concluded that low-field MRI poorly depicts parasellar areas and smaller tumors, in comparison with postoperative higher-field MRIs. ${ }^{2,10}$

Higher-field iMRI ( $3 \mathrm{~T}$ ) has led to greater extent of tumor resection in $11 \%-60 \%$ of cases utilizing either microscopic or endoscopic visualization. ${ }^{6}$ High spatial resolution with high-field magnets can be important for the depiction of pituitary pathologies: small microadenomas may be invisible on standard MR images because of limited resolution. Parasellar extension into the cavernous sinuses is often imaged unsatisfactorily at standard (1.0- to 1.5-T) field strengths. High-field MRI offers the advantage of a higher signal-to-noise ratio, providing higher spatial resolution and a proper image quality within acceptable scanning times. ${ }^{23}$ High-field MRI is superior in detecting microadenomas and in delineating normal anatomy, including compressed or displaced normal pituitary gland. 

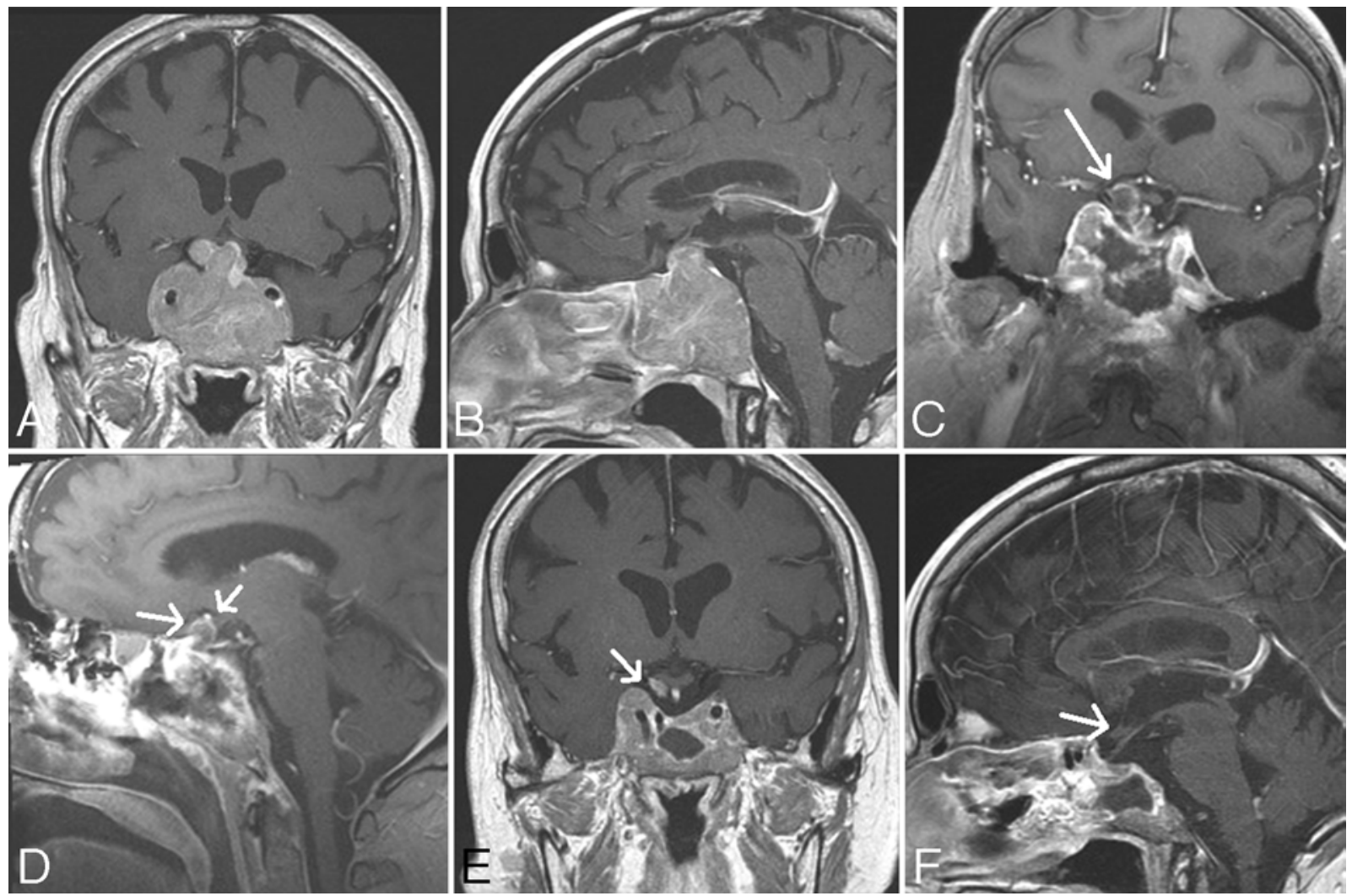

FIG. 7. Case 11. This patient presented with acromegaly, visual loss, and headache and was found to have a macroadenoma invading the bilateral cavernous sinuses and sphenoid sinus and compressing the optic chiasm as shown in the preoperative coronal (A) and sagittal (B) T1-weighted MR images. STR was planned but on intraoperative post-gadolinium T1-weighted MRI (coronal image in $\mathbf{C}$ and sagittal in D), a hypointense nodule of tumor was seen to persistently compress the right optic nerve and chiasm (white arrows in $\mathrm{C}$ and $\mathrm{D}$ ). The nodule was subsequently removed. The postoperative Gd-enhanced T1-weighted MR images obtained 3 months after surgery ( $E$ and $\mathbf{F}$, coronal and sagittal, respectively) demonstrate expected residual tumor in the bilateral cavernous sinuses and even along the right optic chiasm (white arrow), however, remarkable decompression of the optic apparatus (white arrow) was achieved.

Furthermore, detailed analysis of high-field MRI studies can be instrumental in developing surgical strategies in cases in which lesions are invading the medial border of the cavernous sinus or encasing the optic nerves and chiasm and the intracavernous cranial nerves. ${ }^{23}$

The combined utility of endoscopy and iMRI in pituitary surgery has been reviewed in a few surgical series (Table 4). Theodosopoulos et al..$^{28}$ demonstrated in their series of 27 patients with pituitary macroadenomas imaged with $0.3-\mathrm{T}$ MRI, that endoscopy correctly predicted the extent of resection in 23 cases (85\%) and iMRI led to further resection in 3 (11\%). They concluded that endoscopy alone could sufficiently supplant the need for iMRI. Schwartz et al. ${ }^{26}$ reported on a series of 15 cases of pituitary macroadenoma in which purely endoscopic endonasal resection was performed utilizing 0.12-T iMRI; in 3 cases (20\%), iMRI led to further resection. Netuka et al. ${ }^{19}$ described their 1-year experience with 3-T iMRI and pituitary surgery. They found that even in cases in which subtotal resection was planned, further resection was performed in $48.7 \%$ of the cases as a result of iMRI detection of residual tumor; in the group of patients undergoing planned radical resection, iMRI led to additional resection in $22.4 \%$ of cases. The authors concluded that with endoscopy, although less often than with microscopy, iMRI is advantageous in maximizing tumor resection. In our current series of 20 pituitary macroadenoma cases, the single diagnostic dilemma that arose was in differentiating postoperative blood products from residual nonenhancing tumor. This is due in part to the fact that the signal characteristics of blood products can easily mimic those of nonenhancing tumor, as intracellular deoxyhemoglobin is T1 and T2 isointense to normal brain in signal, very similar to nonenhancing tumor. Use of sequences such as GRE (gradient recall echo) or SWI (susceptibility-weighted imaging) is hampered by blooming artifact arising from the air-soft tissue interface, which is present along the posterior wall of the sphenoid sinus. In the first 2 cases in our series, dynamic contrast-enhanced MRI was used in an effort to differentiate these 2 entities. The same diagnostic dilemma arose, however, with blood products mimicking nonenhancing tumor. Thus, in equivocal cases of questionable minute residual tumor burden, an individualized risk-benefit analysis must be performed by the surgeon to weigh the risk of reoperation versus the risk of residual disease.

In our series, iMRI succeeded in maximizing extent of 
TABLE 2. Surgical results, iMRI findings, and endoscopic findings

\begin{tabular}{|c|c|c|c|c|c|c|c|c|}
\hline $\begin{array}{l}\text { Case } \\
\text { No. }\end{array}$ & $\begin{array}{c}\text { Goal of } \\
\text { Op }\end{array}$ & $\begin{array}{l}\text { Pre-iMRI Surgeon } \\
\text { Interp }\end{array}$ & iMRI Interp & $\begin{array}{l}\text { Post-iMRI Surgeon } \\
\text { Findings }\end{array}$ & $\begin{array}{l}\text { Correct iMRI } \\
\text { Interp? }\end{array}$ & $\begin{array}{c}\text { Separate } \\
\text { Path Result }\end{array}$ & $\begin{array}{l}\text { Expected } \\
\text { Finding? }\end{array}$ & $\begin{array}{l}\text { Initial } \rightarrow \\
\text { Final EOR }\end{array}$ \\
\hline 1 & GTR & No residual disease & $\begin{array}{l}\text { Small residual tumor } \\
\text { in rt sellar floor, } \\
\text { optic chiasm } \\
\text { decompressed }\end{array}$ & $\begin{array}{l}\text { Residual removed from } \\
\text { rt inferior/medial CS } \\
\text { wall \& sellar floor }\end{array}$ & Yes & $\begin{array}{l}\mathrm{GH} \text { ad- } \\
\text { enoma }\end{array}$ & Unexpected & $\mathrm{NTR} \rightarrow \mathrm{GTR}$ \\
\hline 2 & GTR & $\begin{array}{l}\text { No residual disease, } \\
\text { dural invasion, ex- } \\
\text { cellent diaphrag- } \\
\text { ma prolapse }\end{array}$ & $\begin{array}{l}\text { Indeterminate: small } \\
\text { residual or blood; } \\
\text { optic chiasm } \\
\text { decompressed }\end{array}$ & $\begin{array}{l}\text { Specimen removed } \\
\text { from rt sellar floor }\end{array}$ & No & $\begin{array}{l}\text { Blood prod- } \\
\text { ucts }\end{array}$ & Expected & GTR \\
\hline 3 & GTR & $\begin{array}{l}\text { No residual disease, } \\
\text { excellent dia- } \\
\text { phragma prolapse }\end{array}$ & $\begin{array}{l}\text { No residual,optic } \\
\text { chiasm decom- } \\
\text { pressed }\end{array}$ & No residual & Yes & NA & Expected & GTR \\
\hline 4 & STR & $\begin{array}{l}\text { Residual along } \\
\text { ACAs/CS }\end{array}$ & $\begin{array}{l}\text { Residual encasing } \\
\text { ACAs/CS, optic } \\
\text { chiasm decom- } \\
\text { pressed }\end{array}$ & $\begin{array}{l}\text { Residual encasing } \\
\text { ACAs/CS }\end{array}$ & Yes & NA & Expected & STR \\
\hline 5 & STR & $\begin{array}{l}\text { Residual along rt } \\
\text { CS/ICA, diaphrag- } \\
\text { ma prolapse }\end{array}$ & $\begin{array}{l}\text { Residual along rt CS/ } \\
\text { ICA, optic chiasm } \\
\text { decompressed }\end{array}$ & Residual in rt CS/ICA & Yes & NA & Expected & STR \\
\hline 6 & GTR & $\begin{array}{l}\text { No residual disease, } \\
\text { excellent dia- } \\
\text { phragma prolapse }\end{array}$ & $\begin{array}{l}\text { No residual, optic } \\
\text { chiasm decom- } \\
\text { pressed }\end{array}$ & No residual & Yes & NA & Expected & GTR \\
\hline 7 & GTR & $\begin{array}{l}\text { No residual disease, } \\
\text { excellent dia- } \\
\text { phragma prolapse }\end{array}$ & $\begin{array}{l}\text { Large suprasellar } \\
\text { residual tumor, } \\
\text { optic chiasm } \\
\text { compression }\end{array}$ & $\begin{array}{l}\text { Suprasellar tumor } \\
\text { apparent after tumor } \\
\text { capsule opened \& } \\
\text { removed; true di- } \\
\text { aprhagma/hardened } \\
\text { arachnoid prolapsed } \\
\text { into sellar defect w/o } \\
\text { CSF leak }\end{array}$ & Yes & $\begin{array}{l}\text { Null cell } \\
\quad \text { adenoma }\end{array}$ & Unexpected & $\mathrm{STR} \rightarrow \mathrm{GTR}$ \\
\hline 8 & GTR & $\begin{array}{l}\text { No residual disease, } \\
\text { excellent dia- } \\
\text { phragma prolapse }\end{array}$ & $\begin{array}{l}\text { No residual, optic } \\
\text { chiasm decom- } \\
\text { pression }\end{array}$ & No residual & Yes & NA & Expected & GTR \\
\hline 9 & NTR & $\begin{array}{l}\text { No residual disease, } \\
\text { excellent dia- } \\
\text { phragma prolapse }\end{array}$ & $\begin{array}{l}\text { Indeterminate: small } \\
\text { residual or blood, } \\
\text { optic chiasm } \\
\text { decompression }\end{array}$ & $\begin{array}{l}\text { Specimen removed } \\
\text { from rt medial CS }\end{array}$ & No & $\begin{array}{l}\text { Blood Prod- } \\
\text { ucts }\end{array}$ & Expected & GTR \\
\hline 10 & NTR & $\begin{array}{l}\text { No residual disease, } \\
\text { excellent dia- } \\
\text { phragma prolapse }\end{array}$ & $\begin{array}{l}\text { Small residual on } \\
\text { It medial CS/ } \\
\text { ICA, optic chiasm } \\
\text { decompression }\end{array}$ & $\begin{array}{l}\text { Small residual removed } \\
\text { along medial CS } \\
\text { wall, lateral CS left } \\
\text { alone }\end{array}$ & Yes & $\begin{array}{l}\text { Null cell } \\
\quad \text { adenoma }\end{array}$ & Unexpected & $\mathrm{NTR} \rightarrow \mathrm{NTR}$ \\
\hline 11 & STR & $\begin{array}{l}\text { Expected residual in } \\
\text { bilat CS }\end{array}$ & $\begin{array}{l}\text { Bilat CS invasion } \\
\text { \& rt suprasellar } \\
\text { nodule, persistent } \\
\text { optic chiasm \& } \\
\text { rt optic nerve } \\
\text { compression }\end{array}$ & $\begin{array}{l}\text { Removed rt suprasel- } \\
\quad \text { lar nodule }\end{array}$ & Yes & $\begin{array}{l}\mathrm{GH}+\mathrm{PRL} \\
\quad \text { adenoma }\end{array}$ & Unexpected & $\mathrm{STR} \rightarrow \mathrm{STR}$ \\
\hline 12 & GTR & $\begin{array}{l}\text { No residual disease, } \\
\text { inverted dia- } \\
\text { phragma }\end{array}$ & $\begin{array}{l}\text { Hypointense It supra- } \\
\text { sellar nodule }\end{array}$ & $\begin{array}{l}\text { Removed specimen } \\
\text { along diaphragma/ } \\
\text { gland fold }\end{array}$ & Yes & $\begin{array}{l}\text { Null cell } \\
\quad \text { adenoma }\end{array}$ & Unexpected & NTR $\rightarrow$ GTR \\
\hline 13 & GTR & $\begin{array}{l}\text { No residual disease, } \\
\text { excellent dia- } \\
\text { phragma prolapse }\end{array}$ & $\begin{array}{l}\text { No residual, optic } \\
\text { chiasm compres- } \\
\text { sion }\end{array}$ & No residual & Yes & NA & Expected & GTR \\
\hline
\end{tabular}

$\mathrm{ACA}=$ anterior cerebral artery; $\mathrm{CS}$ = cavernous sinus; $\mathrm{EOR}$ = extent of resection; ICA = internal carotid artery; interp = interpretation; NA = not applicable; path = pathology. 
TABLE 3. Perioperative complications and surgical outcomes

\begin{tabular}{|c|c|c|c|c|c|}
\hline Case No. & Diagnosis & Intraop CSF Leak? & Postop Complications & Remission & 12-Wk Postop MRI \\
\hline 1 & $\mathrm{GH}$ & No & - & Yes & No residual \\
\hline 2 & Null cell & Yes & - & NA & No residual \\
\hline 3 & Silent GH & No & - & NA & No residual \\
\hline 4 & $\mathrm{GH}$ & Yes & - & Adjuvant sandostatin & Stable residual \\
\hline 5 & Null cell & Yes & - & NA & Stable residual \\
\hline 6 & $\mathrm{GH}$ & No & New secondary hypothyroidism & Yes & No residual \\
\hline 7 & Null cell & Yes & - & NA & No residual \\
\hline 8 & Null cell & No & - & NA & No residual \\
\hline 9 & Null cell & No & New hypoadrenalism, delayed sinusitis & NA & Stable residual \\
\hline 10 & Null cell & Yes & - & NA & No residual \\
\hline 11 & GH PRL & No & - & $\begin{array}{l}\text { Adjuvant radiation \& soma- } \\
\text { tostatin analog }\end{array}$ & Stable residual \\
\hline 12 & Null cell & No & - & NA & No residual \\
\hline 13 & Null cell & Yes & - & NA & No residual \\
\hline 14 & Null cell & No & - & NA & No residual \\
\hline 15 & FSH/LH NFA & Yes & - & NA & No residual \\
\hline 16 & LH NFA & No & - & NA & No residual \\
\hline 17 & Null cell & No & - & NA & No residual \\
\hline 18 & Silent ACTH & No & - & NA & No residual \\
\hline 19 & Silent FSH & Yes & - & NA & No residual \\
\hline 20 & Null cell & No & - & NA & No residual \\
\hline
\end{tabular}

resection in 6 patients $(30 \%)$ and increased the proportion of GTRs from $60 \%$ to $80 \%$. Our findings reflect previous studies regarding the utility of iMRI in detecting residual disease. ${ }^{20}$ In Case 7, iMRI detected a large unanticipated residual suprasellar supradiaphragmatic tumor nodule with persistent optic chiasm compression (Fig. 2). Despite what was perceived to be symmetric diaphragmatic prolapse intraoperatively, frank residual tumor was detected and was subsequently removed after entering the presumed diaphragma, which was likely a fold of tumor capsule from supradiaphragmatic tumor (Fig. 3). It is widely felt that descent of the diaphragma sellae serves as a reference to determine risk of leaving residual tumor, with the goal being symmetric prolapse. Supradiaphragmatic extension of a pituitary adenoma is uncommon ${ }^{7,16}$ and can be difficult to confirm intraoperatively without deliberate incision of the diaphragm.

In Case 1, involving a patient with acromegaly who is now in endocrine remission, further tumor removal after iMRI detection and histological confirmation proved invaluable for raising the likelihood of remission. Confirmation of optic chiasm decompression on iMRI can assure the surgeon that the patient has the best chance of recovery of visual loss. This was demonstrated in all cases by subjective and clinical improvement of postoperative vision. This is consistent with Berkman et al.' $\mathrm{s}^{3}$ obvious conclusions that MRI detection of optic apparatus decompression is prognostic for vision improvement.

Overall, most studies have found iMRI useful by allowing interval evaluation of operative progress, updating

TABLE 4. Endoscopic pituitary surgery and iMRI: review of the literature and extent of resection

\begin{tabular}{|c|c|c|c|c|c|c|}
\hline Authors \& Year & MRI & $\begin{array}{l}\text { No. of Patients \& } \\
\text { Adenoma Type }\end{array}$ & $\begin{array}{l}\text { Unexpected Residual } \\
\text { Tumor Found on iMRI }\end{array}$ & $\begin{array}{l}\text { Eligible for Further } \\
\text { Resection }\end{array}$ & $\begin{array}{c}\text { Pre-iMRI GTR } \rightarrow \\
\text { Post-iMRI GTR }\end{array}$ & $\begin{array}{c}\text { iMRI Led to } \\
\text { Further Resection }\end{array}$ \\
\hline Netuka et al., 2011 & $3.0 \mathrm{~T}$ & $\begin{array}{l}86 \text { (76 macro, } 10 \text { micro) } \\
\text { Intended GTR: } 49 \\
\text { Intended NTR/STR: } 37\end{array}$ & $15.1 \%(13 / 86)$ & $33.7 \%(29 / 86)$ & $69.4 \% \rightarrow 91.8 \%$ & $33.7 \%$ \\
\hline $\begin{array}{l}\text { Theodosopoulos et } \\
\text { al., } 2010\end{array}$ & $0.3 \mathrm{~T}$ & 27 macroadenomas & $14.8 \%(4 / 27)$ & $12.5 \%(3 / 27)$ & $62.9 \% \rightarrow 70 \%$ & $11 \%$ \\
\hline Schwartz et al., 2006 & $0.12 \mathrm{~T}$ & 15 macroadenomas & $20 \%(3 / 15)$ & $20 \%(3 / 15)$ & $80 \% \rightarrow 100 \%$ & $20 \%$ \\
\hline Present study & $3.0 \mathrm{~T}$ & $\begin{array}{l}20 \text { macroadenomas } \\
\text { Intended GTR: } 14 \\
\text { Intended NTR/STR: } 6\end{array}$ & $30 \%(6 / 20)$ & $\begin{array}{l}30 \%(6 / 20) \\
28.6 \%(4 / 14) \\
33.3 \%(2 / 6)\end{array}$ & $60 \% \rightarrow 80 \%$ & $30 \%$ \\
\hline
\end{tabular}


intraoperative navigation registration accounting for brain and tumor shift, excluding any imminent hemorrhagic complications and detecting residual tumor. ${ }^{5}$ Intraoperative MRI can lead to increased rates of GTR without compromising normal pituitary function, and it can also decrease the risk of both hypopituitarism risk and vision loss. ${ }^{3,4,27}$ Jane and Laws, ${ }^{13}$ in a comment on the study by Theodosopoulos et al., ${ }^{28}$ point out that although the endoscope provides superior illumination, magnification, and clarity, its advantages remain limited due to the dependence upon the surgeon's interpretation of intraoperative findings. Pituitary tumors, although frequently distinct from normal gland, can be difficult to differentiate visually even as the operation progresses, because of evolving tumor and gland hyperemia and varying tumor consistencies. Indeed, there is still no evidence in the neurosurgical literature proving that extent of resection of a nonfunctioning adenoma directly correlates with long-term outcome or recurrence; nevertheless, the goal for both nonfunctioning macroadenomas, and particularly for functioning adenomas is safe GTR.

\section{Limitations}

There are several limitations of the use of iMRI for pituitary tumor surgery. The expenses involved in purchasing and installing an iMRI unit as well as the ancillary support staff can be prohibitive. Many small academic medical centers as well as community hospitals may not have the necessary financial leverage. Our current study did not review institutional costs or billed charges. Although iMRI provides a detailed view of sellar and parasellar structures, differentiating blood from tumor and identifying devascularized tumor remains a challenge that can potentially be overcome as advances with dynamic sequences, delayed contrast enhancement, and preoperative comparison are implemented. The presence of blood products can often complicate interpretation of the imaging findings, often resembling residual disease. ${ }^{31}$ We have found that interpretation of images can be an important limiting factor, and it necessitates a multidisciplinary approach with a comprehensive discussion between the neurosurgeon and neuroradiologist. Finally, delays in surgery using iMRI initially posed a problem in over-extending the amount of time that the patient was in a state of general anesthesia. With dedicated imaging teams, this limitation has been mitigated at our institution, and our average iMRI acquisition time is 21.5 minutes.

\section{Conclusions}

Despite advances in visualization provided by endoscopy, the incidence of residual disease after resection of sellar lesions can be frustrating for the surgeon and potentially place patients at risk for additional surgery. We found that iMRI can be useful in detecting unexpected residual tumor, in our experience up to $30.0 \%$, particularly when the location is supradiaphragmatic, adjacent to and involving the cavernous sinus wall, in the recesses of the tumor capsule, along the normal gland and sellar walls. In select cases, a combination of endoscopy and iMRI may help to maximize the extent of tumor resection while preserving important parasellar neurovascular structures.

\section{References}

1. Barahona MJ, Sojo L, Wägner AM, Bartumeus F, Oliver B, Cano P, et al: Determinants of neurosurgical outcome in pituitary tumors. J Endocrinol Invest 28:787-794, 2005

2. Bellut D, Hlavica M, Schmid C, Bernays RL: Intraoperative magnetic resonance imaging-assisted transsphenoidal pituitary surgery in patients with acromegaly. Neurosurg Focus 29(4):E9, 2010

3. Berkmann S, Fandino J, Müller B, Remonda L, Landolt H: Intraoperative MRI and endocrinological outcome of transsphenoidal surgery for non-functioning pituitary adenoma. Acta Neurochir (Wien) 154:639-647, 2012

4. Berkmann S, Fandino J, Zosso S, Killer HE, Remonda L, Landolt $\mathrm{H}$ : Intraoperative magnetic resonance imaging and early prognosis for vision after transsphenoidal surgery for sellar lesions. J Neurosurg 115:518-527, 2011

5. Bohinski RJ, Warnick RE, Gaskill-Shipley MF, Zuccarello M, van Loveren HR, Kormos DW, et al: Intraoperative magnetic resonance imaging to determine the extent of resection of pituitary macroadenomas during transsphenoidal microsurgery. Neurosurgery 49:1133-1144, 2001

6. Buchfelder M, Schlaffer SM: Intraoperative magnetic resonance imaging during surgery for pituitary adenomas: pros and cons. Endocrine 42:483-495, 2012

7. Campero A, Martins C, Yasuda A, Rhoton AL Jr: Microsurgical anatomy of the diaphragma sellae and its role in directing the pattern of growth of pituitary adenomas. Neurosurgery 62:717-723, 2008

8. Carrau RL, Jho HD, Ko Y: Transnasal-transsphenoidal endoscopic surgery of the pituitary gland. Laryngoscope 106:914-918, 1996

9. D’Haens J, Van Rompaey K, Stadnik T, Haentjens P, Poppe $\mathrm{K}$, Velkeniers B: Fully endoscopic transsphenoidal surgery for functioning pituitary adenomas: a retrospective comparison with traditional transsphenoidal microsurgery in the same institution. Surg Neurol 72:336-340, 2009

10. Gerlach R, du Mesnil de Rochemont R, Gasser T, Marquardt G, Reusch J, Imoehl L, et al: Feasibility of Polestar N20, an ultra-low-field intraoperative magnetic resonance imaging system in resection control of pituitary macroadenomas: lessons learned from the first 40 cases. Neurosurgery 63:272285,2008

11. Hamilton DK, Vance ML, Boulos PT, Laws ER: Surgical outcomes in hyporesponsive prolactinomas: analysis of patients with resistance or intolerance to dopamine agonists. Pituitary 8:53-60, 2005

12. Hardy J: Transsphenoidal hypophysectomy. J Neurosurg 34:582-594, 1971

13. Jane JA Jr, Laws ER Jr: Editorial. Endoscopy versus MR imaging. J Neurosurg 112:734-735, 2010

14. Jane JA Jr, Thapar K, Kaptain GJ, Maartens N, Laws ER Jr: Pituitary surgery: transsphenoidal approach. Neurosurgery 51:435-444, 2002

15. Jones J, Ruge J: Intraoperative magnetic resonance imaging in pituitary macroadenoma surgery: an assessment of visual outcome. Neurosurg Focus 23(5):E12, 2007

16. Kinoshita Y, Tominaga A, Arita K, Hama S, Sakoguchi T, Sugiyama K, et al: Supra-diaphragmatic pituitary adenoma removed through the trans-tuberculum sellae approach. Case report. Neurol Med Chir (Tokyo) 52:91-95, 2012

17. Laws ER, Vance ML, Thapar K: Pituitary surgery for the management of acromegaly. Horm Res 53 (Suppl 3):71-75, 2000

18. Martin CH, Schwartz R, Jolesz F, Black PM: Transsphenoidal resection of pituitary adenomas in an intraoperative MRI unit. Pituitary 2:155-162, 1999

19. Netuka D, Masopust V, Belšán T, Kramář F, Beneš V: One year experience with $3.0 \mathrm{~T}$ intraoperative MRI in pituitary surgery. Acta Neurochir Suppl 109:157-159, 2011

20. Nimsky C, Ganslandt O, Kober H, Buchfelder M, Fahlbusch 
$\mathrm{R}$ : Intraoperative magnetic resonance imaging combined with neuronavigation: a new concept. Neurosurgery 48:1082-1091, 2001

21. Paterno V, Fahlbusch R: High-field iMRI in transsphenoidal pituitary adenoma surgery with special respect to typical localization of residual tumor. Acta Neurochir (Wien) 156:463-474, 2014

22. Pergolizzi RS Jr, Nabavi A, Schwartz RB, Hsu L, Wong TZ, Martin C, et al: Intra-operative MR guidance during transsphenoidal pituitary resection: preliminary results. J Magn Reson Imaging 13:136-141, 2001

23. Pinker K, Ba-Ssalamah A, Wolfsberger S, Mlynarik V, Knosp E, Trattnig S: The value of high-field MRI (3T) in the assessment of sellar lesions. Eur J Radiol 54:327-334, 2005

24. Prevedello DM, Pouratian N, Sherman J, Jane JA Jr, Vance ML, Lopes MB, et al: Management of Cushing's disease: outcome in patients with microadenoma detected on pituitary magnetic resonance imaging. J Neurosurg 109:751-759, 2008

25. Rotenberg B, Tam S, Ryu WH, Duggal N: Microscopic versus endoscopic pituitary surgery: a systematic review. Laryngoscope 120:1292-1297, 2010

26. Schwartz TH, Stieg PE, Anand VK: Endoscopic transsphenoidal pituitary surgery with intraoperative magnetic resonance imaging. Neurosurgery 58 (1 Suppl):ONS44-ONS51, 2006

27. Szerlip NJ, Zhang YC, Placantonakis DG, Goldman M, Colevas KB, Rubin DG, et al: Transsphenoidal resection of sellar tumors using high-field intraoperative magnetic resonance imaging. Skull Base 21:223-232, 2011

28. Theodosopoulos PV, Leach J, Kerr RG, Zimmer LA, Denny AM, Guthikonda B, et al: Maximizing the extent of tumor resection during transsphenoidal surgery for pituitary macroadenomas: can endoscopy replace intraoperative magnetic resonance imaging? J Neurosurg 112:736-743, 2010

29. Vitaz TW, Inkabi KE, Carrubba CJ: Intraoperative MRI for transphenoidal procedures: short-term outcome for 100 consecutive cases. Clin Neurol Neurosurg 113:731-735, 2011

30. Zaidi H, Bohl M, Awad AW, Chapple K, Knecht L, Jahnke H, et al: Comparison of extent of tumor resection and endocrine outcomes for nonfunctioning pituitary adenomas of a less experienced surgeon using a fully endoscopic transsphenoidal surgery technique to a very experienced surgeon using a microscopic transsphenoidal surgical technique. Neurosurgery 62 (Suppl 1):208-209, 2015 (Abstract)

31. Zaidi HA, Chowdhry SA, Wilson DA, Spetzler RF: The dilemma of early postoperative magnetic resonance imaging: when efficiency compromises accuracy: case report. Neurosurgery 74:E335-E340, 2014

\section{Disclosures}

The authors report no conflict of interest concerning the materials or methods used in this study or the findings specified in this paper.

\section{Supplemental Information Current Affiliations}

Dr. Barkhoudarian: Department of Neurosurgery, John Wayne Cancer Institute, Santa Monica, CA.

Dr. Litvack: Department of Neurosurgery, George Washington University, Washington, DC.

Dr. De Los Reyes: Department of Neurosurgery, Loma Linda University, Loma Linda, CA.

\section{Author Contributions}

Conception and design: all authors. Acquisition of data: Zaidi, De Los Reyes, Bi. Analysis and interpretation of data: Zaidi, De Los Reyes. Drafting the article: Laws, Zaidi, De Los Reyes. Critically revising the article: Laws, Zaidi, De Los Reyes, Barkhoudarian, Litvack, Dunn. Reviewed submitted version of manuscript: Laws, Zaidi, De Los Reyes, Barkhoudarian, Rincon-Torroella, Mukundan, Dunn. Statistical analysis: Zaidi, De Los Reyes, Mukundan. Administrative/technical/material support: Laws. Study supervision: Laws.

\section{Correspondence}

Edward R. Laws Jr., Brigham and Women's Hospital, 15 Francis St., PBB-3, Boston, MA 02115. email: elaws@partners.org. 